\title{
Continuation of epidermal growth factor receptor tyrosine kinase inhibitor treatment prolongs disease control in non- small-cell lung cancers with acquired resistance to EGFR tyrosine kinase inhibitors
}

\author{
Qi Chen ${ }^{1,2,3}$, Qi Quan ${ }^{1,2,3}$, Lingyu Ding ${ }^{1,2,3}$, Xiangchan Hong ${ }^{1,2,3}$, Ningning Zhou ${ }^{1,2,3}$, \\ Ying Liang ${ }^{1,2,3}$, Haiying $\mathbf{W u}^{1,2,3}$ \\ ${ }^{1}$ State Key Laboratory of Oncology in South China, Guangzhou, China \\ ${ }^{2}$ Department of Oncology, Sun Yat-Sen University Cancer Center, Guangzhou, China \\ ${ }^{3}$ Collaborative Innovation Center of Cancer Medicine, Sun Yat-Sen University Cancer Center, Guangzhou, China \\ Correspondence to: \\ Haiying Wu, e-mail: chenqi4608@163.com \\ Keywords: non-small-cell lung cancer, acquired resistance, continuation of epidermal growth factor receptor tyrosine kinase \\ inhibitors, beyond PD, local treatment \\ Received: April 21, 2015 \\ Accepted: June 26, 2015 \\ Published: July 09, 2015
}

\section{ABSTRACT}

Objectives: Patients with non-small-cell lung cancer (NSCLC) develop acquired resistance to epidermal growth factor receptor tyrosine kinase inhibitors (EGFR TKIs) after tumor regression. No approved targeted therapies are currently available after initial EGFR TKI treatment. This study investigated the efficacy of continuing EGFR TKI therapy with local treatments for patients with NSCLC and local progression or minimal/slow progression on TKI therapy.

Materials and Methods: Fifty-five patients with NSCLC treated with EGFR TKIs and developed acquired resistance to the drug were included. Initial response to target therapy, median progression free survival (PFS1), progression pattern, and first progression site were assessed. Median progression free survival to physician assessment progression (PFS2) and difference between PFS1 and PFS2 (PFS difference) were also recorded.

Results and Conclusion: PFS1 was 11.2 months, PFS2 was 20.3 months, and PFS difference was 8.3 months. Nineteen patients (34.5\%) who manifested progression received local therapy, and $16(28.6 \%)$ underwent rebiopsy after progression with six positive EGFR T790M mutations detected. Cox proportional hazards regression model showed that only the first line of treatment was significantly correlated with PFS difference. NSCLC patients with acquired resistance to EGFR TKIs could benefit from the same TKI therapy through months to years of disease control.

\section{INTRODUCTION}

Epidermal growth factor receptor tyrosine kinase inhibitors (EGFR TKIs) are the standard of care in EGFR-mutant non-small-cell lung cancer because of its superior efficacy over chemotherapy. [1, 2] However, patients who initially responded to EGFR-TKIs would eventually present a median of 10-14 months in response evaluation criteria in solid tumors progressive disease
(RECIST PD), [3-5] which clinically manifests as tumor progression and symptomatic decline.

Acquired resistance to EGFR TKIs is caused by several molecular mechanisms, including the presence of the T790M missense mutation, MET amplification, and transformation to small-cell histology. [6] Currently, no approved targeted therapies or efficient treatments are available for patients upon progression. 
We selected NSCLC patients with local progression or minimal/slow progression on TKI therapy in our study. There is ongoing benefit from the targeted therapy in other sites of (non-progressing) disease due to continuing suppression of sensitive clones that have not yet developed acquired resistance. Consistent with this, patients with EGFR-MT disease who progress often experience a disease flare when the EGFR-TKI is discontinued, and re-challenge of these patients with the same EGFR-TKI after only a short time off therapy can lead to re-responses. [7-9] In addition, treatment beyond progression of EGFRMT NSCLC with an EGFR-TKI has been associated with improved overall survival, compared to those in whom the TKI was permanently discontinued. [10] Analogous benefits of continuation of trastuzumab beyond progression have been well described in metastatic breast cancer. [11]

This clinical phenomenon has impelled physicians to continue TKI therapy beyond progression on EGFR TKI agents. Ongoing prospective studies evaluate strategies of continuation of erlotinib beyond RECIST progression (ASPIRATION) [12] and gefitinib combined with chemotherapy beyond RECIST progression (IMPRESS); [13] nevertheless, results remain inconclusive. Therefore, we designed this study to investigate the efficacy and safety of continuation of EGFR TKI therapy with necessary local treatments for NSCLC patients with local progression or minimal/ slow progression on TKI therapy. The potential factors that affect the effectiveness of this strategy were also discussed.

\section{RESULTS}

\section{Patient characteristics}

From December 2010 to January 2015, patients from the Sun Yat-Sen University Cancer Center with histologically confirmed stage IIIB/IV NSCLC were included in this study. We initially screened 261 patients (Figure 1) with RECIST progression on EGFR TKIs, and 55 patients who satisfied the inclusion criteria were eventually analyzed. The clinical and molecular baseline characteristics of the 55 patients are shown in Table 1. The patients were composed of 23 men and 32 women, and most of them were non-smokers $(44,80 \%)$. The tumor pathology of the patients was all adenocarcinoma, except for two squamous cell carcinomas. Seventeen patients were older than 60 years. Forty-three cases $(78.2 \%)$ harbored EGFR-sensitive mutations (including 23 exon 19 deletions and 20 exon 21 L858R mutations), four cases (7.3\%) with wild type, and eight cases with unknown mutational status (14.5\%). As shown in Table 1, lung $(44 / 55,80 \%)$, brain $(4 / 55,7.3 \%)$, and bone $(4 / 55,7.3 \%)$ were the leading sites of progression. A patient simultaneously developed brain and lung progression, and five patients successively developed progression in the two sites. As for local treatments $(19 / 55,34.5 \%)$ upon progression, four patients $(4 / 19,21.1 \%)$ received lung radiofrequency ablation after pulmonary progression, one patient $(1 / 19,5.3 \%)$ received lung stereotactic radiotherapy, and four $(4 / 19,26.3 \%)$ patients with pleural effusion progression received ultrasound-guided drainage

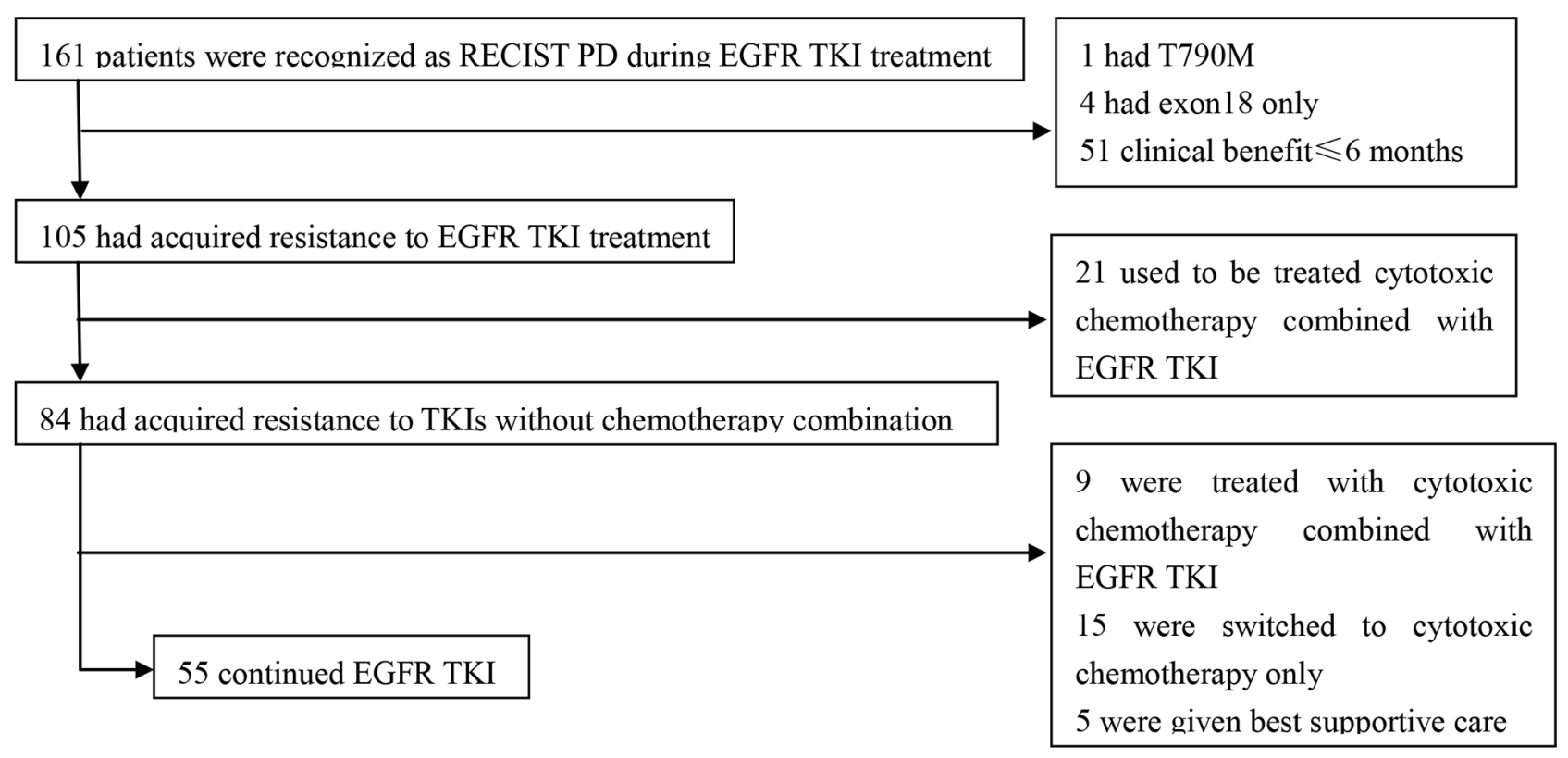

Figure 1: Flowchart of patient selection. EGFR, epidermal growth factor receptor; TKI, tyrosine kinase inhibitor; RECIST, Response Evaluation Criteria in Solid Tumors; PD, progression disease. 
Table 1: Patients characteristics $(n=55)$

$N$

$\%$

\begin{tabular}{|c|c|c|}
\hline \multicolumn{3}{|l|}{$\operatorname{Age}(y)$} \\
\hline Median (range) & $55(31-77)$ & \\
\hline \multicolumn{3}{|l|}{ Gender } \\
\hline Female & 32 & 58.2 \\
\hline Male & 23 & 41.8 \\
\hline \multicolumn{3}{|l|}{ Smoking history } \\
\hline Never-Smoker & 44 & 80.0 \\
\hline Former/smoker & 11 & 20.0 \\
\hline \multicolumn{3}{|l|}{ Pathology } \\
\hline Adenocarcinoma & 53 & 96.4 \\
\hline squamous cell carcinoma & 2 & 3.6 \\
\hline \multicolumn{3}{|l|}{ EGFR mutation status } \\
\hline Exon 19 deletion & 23 & 41.8 \\
\hline Exon 21 L858R & 20 & 36.4 \\
\hline Wild type & 4 & 7.3 \\
\hline Unknown & 8 & 14.5 \\
\hline \multicolumn{3}{|l|}{ Disease stage } \\
\hline Stage IV & 43 & 78.2 \\
\hline Recurrent & 12 & 21.8 \\
\hline \multicolumn{3}{|l|}{ Initiation of EGFR-TKI } \\
\hline 1st line & 30 & 54.5 \\
\hline 2/3rd line & 25 & 45.5 \\
\hline \multicolumn{3}{|l|}{ TKI regimen choice } \\
\hline Erlotinib & 37 & 67.3 \\
\hline Gefitinib/Icotinib & 18 & 32.7 \\
\hline \multicolumn{3}{|l|}{ Local therapy } \\
\hline No & 36 & 65.5 \\
\hline Yes & 19 & 34.5 \\
\hline \multicolumn{3}{|l|}{ Site of RECIST PD } \\
\hline Lung & 44 & 80.0 \\
\hline Bone & 4 & 7.3 \\
\hline Brain & 4 & 7.3 \\
\hline Lymph node & 1 & 1.8 \\
\hline Visceral (liver, adrenal gland) & 2 & 3.6 \\
\hline \multicolumn{3}{|l|}{ Progression type } \\
\hline Local progression & 10 & 18.2 \\
\hline Slow/Minimal progression & 45 & 81.8 \\
\hline
\end{tabular}

EGFR, epidermal growth factor receptor; TKI, tyrosine kinase inhibitor; RECIST, Response Evaluation Criteria in Solid Tumors; PD, progression disease. 
plus bleomycin injection to the thoracic cavity. In patients with CNS progression, four received whole brain radiation therapy (WBRT), one received gamma knife radiosurgery, one sequentially received WBRT and gamma knife radiosurgery, and one received brain metastases resection surgery and WBRT surgery. Three of four patients $(3 / 4,75 \%)$ with bone metastasis progression continued EGFR TKI treatment with bone radiation therapy.

Sixteen patients $(28.6 \%)$ had rebiopsy after resistance at the following sites: pleural effusion $(6 / 16,37.5 \%)$, lung $(5 / 16,31.3 \%)$, supraclavicular lymph nodes $(3 / 16,18.8 \%)$, ascetic fluid $(1 / 16,6.3 \%)$, and brain metastases (1/16, 6.3\%). Of 16 patients, 14 (87.5\%) had their rebiopsy tissue examined by molecular tests (Table 2), three patients underwent EGFR mutation and MET amplification tests, and 11 patients had EGFR mutation tests. Among these 14 EGFR mutation tests samples, we detected six (42.9\%) positive EGFR T790M mutations with one sensitive mutation and two (14.3\%) wild types. For the two wild-type rebiopsy patients, their rebiopsy sites were both in the lung. One patient harbored EGFR mutation of L858R in exon 21 in lung biopsy tissues, and the other patient had wild-type EGFR in brain metastasis tissues; TKI therapy resulted in stable disease in the lung for 8.25 months. One $(33.3 \%)$ positive result was detected in the MET amplification tests, and the rebiopsy sample of this patient harbored the T790M mutation.

\section{Survival data}

Data cut-off date for follow-up was January 23, 2015, and the median follow-up duration was 20.93 months from the initial TKI therapy to physician assessment PD (range: 8.51-81.87 months). At the time of the data cut off, 23 patients $(41.1 \%)$ exhibited physician assessment PD and 11 (19.6\%) died. The median progression free survival (PFS1) was 11.2 months (95\% CI, 9.4-14.7 months), the median PFS2 was 20.3 months (95\% CI, 17.1-24.1 months; Table 3), and the median PFS difference was 8.3 months (95\% CI, 6.4-10.2 months; Table 3 ). Hence, $80 \%$ of patients can further benefit from continuation of EGFR TKI treatment for more than 3 months. Moreover, disease control persisted for more than 12 months in $26 \%$ of patients without significant clinical progression.

Smoking history, gender, age, pathology, initial TKI efficacy, TKI regimen, first line of treatment, disease stage, and EGFR mutation status were used as variables in

Table 2: EGFR mutation status before and after RECIST PD

\begin{tabular}{|c|c|c|c|c|}
\hline patient & first biopsy site & $\begin{array}{l}\text { EGFR mutation status } \\
\text { before RECIST PD }\end{array}$ & rebiopsy site & $\begin{array}{l}\text { EGFR mutation status after } \\
\text { RECIST PD }\end{array}$ \\
\hline 1 & lung & exon 19 deletion & hydrothorax & exon 19 deletion \\
\hline 2 & lung & exon 19 deletion & ascites & exon 19 deletion \\
\hline 3 & lung & unkonwn & hydrothorax & exon 19 deletion \\
\hline 4 & lung & L858R & supraclavicular lymph nodes & L858R \\
\hline 5 & brain & wild type & lung & wild type \\
\hline 6 & $\begin{array}{l}\text { supraclavicular } \\
\text { lymph nodes }\end{array}$ & exon 19 deletion & lung & $\begin{array}{l}\text { exon } 19 \text { deletion+T790M } \\
\text { mutation }\end{array}$ \\
\hline 7 & hydrothorax & L858R & hydrothorax & L858R \\
\hline 8 & lung & exon 19 deletion & supraclavicular lymph nodes & $\begin{array}{l}\text { exon } 19 \text { deletion }+\mathrm{T} 790 \mathrm{M} \\
\text { mutation }\end{array}$ \\
\hline 9 & lung & L858R & hydrothorax & L858R+T790M mutation \\
\hline 10 & lung & exon 19 deletion & lung & $\begin{array}{l}\text { exon } 19 \text { deletion }+\mathrm{T} 790 \mathrm{M} \\
\text { mutation }\end{array}$ \\
\hline 11 & $\begin{array}{l}\text { supraclavicular } \\
\text { lymph nodes }\end{array}$ & exon 19 deletion & supraclavicular lymph nodes & exon 19 deletion \\
\hline 12 & lung & L858R & lung & wild type \\
\hline 13 & lung & exon 19 deletion & hydrothorax & $\begin{array}{l}\text { exon } 19 \text { deletion+T790M } \\
\text { mutation }\end{array}$ \\
\hline 14 & lung & exon 19 deletion & lung & $\begin{array}{l}\text { exon } 19 \text { deletion, T790M } \\
\text { mutation, MET amplification( }+ \text { ) }\end{array}$ \\
\hline
\end{tabular}

EGFR, epidermal growth factor receptor; RECIST, Response Evaluation Criteria in Solid Tumors; PD, progression disease 
Table 3: Survival data

\begin{tabular}{|l|c|}
\hline \multicolumn{2}{|l|}{ PFS1 } \\
\hline Median $(95 \% \mathrm{CI})$ \\
\hline PFS2 & $11.2(9.4-14.7)$ \\
\hline Median $(95 \% \mathrm{CI})$ & $20.3(17.1-24.1)$ \\
\hline PFS Difference & \\
\hline Median $(95 \% \mathrm{CI})$ & $8.3(6.4-10.2)$ \\
\hline
\end{tabular}

PFS, progression free survival; CI, confidence interval.

univariate analysis. The results demonstrated that female patients, patients who never smoked, and patients who had not undergone chemotherapy before a TKI treatment presented high possibility of achieving effective outcomes with continued EGFR TKI monotherapy (Table 4).

The first line of treatment was significantly correlated with PFS difference (Figure 1) under multivariate Cox proportional hazards regression model (hazard ratio [HR] for chemotherapy vs. TKI, 2.192; 95\% CI, 1.008-4.768, P = 0.0048; Table 4)

The most common adverse event was grade 1 or 2 rash, which affected seven patients (12.7\%), whereas no grade 3 skin rash was observed. Moreover, no dose reduction or discontinuation of TKI caused by unbearable TKI-associated toxicity was required.

\section{DISCUSSION}

Patients who developed local or slow/minimal progression (oligoprogression) after EGFR TKI treatments present unique clinical characteristics. As no approved targeted therapies are currently available for patients with acquired resistance, they choose between standard cytotoxic chemotherapy with or without EGFR TKI continuation or enroll in clinical trials. In this study, continuation of the same EGFR TKI therapy in addition to necessary local therapy (including radiation, ultrasound-guided drainage plus bleomycin injection to thoracic cavity, and surgery) is correlated with a median time to physician assessment progression of 21 months, thus extending disease control by more than 9 months after RECIST progression. The median time to progression in groups choosing pemetrexed plus platinum chemotherapy after prior EGFR TKI treatment failure was 6.1 months. [14] Several factors contributed to the efficacy of the treatment in patients with NSCLS with acquired resistance to EGFR TKI (local or slow/minimal progression); such factors include special clinical course of acquired resistance disease, continuation of TKI therapy for sensitive tumor cells, and potential benefits of local treatment.

Few articles reported the outcomes of continued EGFR TKI for patients with acquired resistance to the targeted therapy. According to Jackman's definition, [15] patients with acquired resistance to EGFR TKIs were classified under a unique patient population. These patients had improved outcomes with continuous EGFR TKI therapy. Moreover, approximately $80 \%$ of the patients harbored a drug sensitivity-associated EGFR mutation site and presented improved surgical outcomes with cytotoxic chemotherapy. $[5,16]$ Even with the development of acquired resistance, these patients with local progression or minimal/slow progression on TKI therapy resulted in long survival, particularly those with the emergence of the T790M mutation, which is correlated with improved beyond-progression outcomes. [17]

All patients in this study continued the same EGFR TKI treatment after progression, which probably contributed to their effective clinical outcomes. A previous study indicated that during the development of acquired resistance to EGFR TKIs, all cells remained oncogene addicted; the most common etiology of acquired resistance was the presence of the T790M mutation in few cells, which were only a small fraction of total alleles, and most cells remained sensitive. [18] This theory could partly explain the effectiveness of TKI therapy after acquired resistance. Moreover, non-stop targeted therapy prevented potential disease flare, which has been reported in patients who discontinued erlotinib or gefitinib after developing acquired resistance. [8,9]

In 2010, a clinical definition of acquired resistance to EGFR-TKIs in NSCLC [15] was proposed for those who responded ( $\geq 6$ months) to initial gefitinib or erlotinib treatment with a drug sensitivity-associated mutation site or objective clinical benefit from treatment with an EGFR TKI. Patients with local or minimal/slow progression to EGFR TKI benefited from continuous targeted treatment. The established clinical definition is reasonable as confirmed in the present research, in which patients with several characteristics exhibited a prolonged PFS of 8.3 months. Moreover, long PFS1 resulted in high PFS difference, which is consistent with the acquired resistance definition. The only significant factor affecting the PFS difference in multivariate Cox proportional hazards regression model is the first line of treatment. 
Table 4: Survival analysis of continued TKI

\begin{tabular}{|c|c|c|c|c|c|}
\hline \multirow[b]{2}{*}{$\boldsymbol{P}$} & \multicolumn{3}{|c|}{ Univariate analysis } & \multicolumn{2}{|c|}{ Multivariate analysis } \\
\hline & PFS1 & PFS2 & PFSDifference & PFSDifference & Hazard ratio $[95 \% \mathrm{CI}]$ \\
\hline gender & 0.206 & 0.136 & 0.164 & & \\
\hline Age $(>60$ y vs. $<60$ y) & 0.367 & 0.722 & 0.855 & & \\
\hline Smoking history & 0.231 & 0.026 & 0.031 & & \\
\hline Pathology & 0.004 & 0.024 & 0.321 & & \\
\hline EGFR mutation status & 0.663 & 0.646 & 0.785 & & \\
\hline $\begin{array}{l}\text { Disease status at } \\
\text { initiation of TKI(Stage } \\
\text { IV vs. Recurrent) }\end{array}$ & 0.417 & 0.112 & 0.078 & & \\
\hline Disease stage & 0.061 & 0.353 & 0.542 & & \\
\hline TKI regimen choice & 0.002 & 0.111 & 0.332 & & \\
\hline Local therapy & / & 0.932 & 0.889 & & \\
\hline Best response to TKI & 0.507 & 0.279 & 0.402 & & \\
\hline $\begin{array}{l}\text { Initiation of EGFR- } \\
\text { TKI(2/3rd line vs. } 1 \text { st } \\
\text { line) }\end{array}$ & 0.023 & 0.248 & 0.035 & 0.048 & $\begin{array}{c}\text { 2.192(2/3rd line vs. } 1 \mathrm{st} \\
\text { line) }[1.008-4.768]\end{array}$ \\
\hline
\end{tabular}

EGFR, epidermal growth factor receptor; TKI, tyrosine kinase inhibitor; PFS, progression free survival; CI, confidence interval.

Thus, patients who did not receive chemotherapy before EGFR-TKIs could present a high PFS difference. Hence, patients who received chemotherapy before EGFR TKI therapy exhibit poor performance at the initiation of targeted therapy, resulting in low PFS1 and PFS differences.

Genomic analysis comparison of rebiopsy and primary tumor samples is shown in Table 4. In 14 patients who underwent rebiopsy and T790M mutation test after resistance, the frequency of EGFR T790M mutation was $42.9 \%$, which is consistent with a previous report. [17] One (33.3\%) positive MET amplification case was found in three tested samples, which could be attributed to limited test cases. No small-cell histologic transformation was detected in the rebiopsy tumor samples. Rebiopsy after development of acquired resistance and genomic analysis of progression sites should be included in routine work because they may provide useful information for tailoring subsequent treatment strategies.

In conclusion, this study showed that continuation of EGFR TKI therapy with necessary local therapy or treatment can be used as a management option for patients who developed oligoprogression during EGFR TKI therapy. Patients with acquired resistance to EGFR TKIs presented a unique clinical course and could benefit from continuation of EGFR TKI treatment, resulting in months to years of disease control and tolerance. However, this study was limited by the small number of enrolled patients and inconclusive overall survival data. A prospective multicenter evaluation of continuation of EGFR-TKI treatment must be performed on patients who developed local or minimal/ slow progression according to the type of resistance mechanisms.

\section{PATIENTS AND METHOD}

\section{Patient eligibility}

Patients with lung cancer who developed acquired resistance to EGFR TKI with documented slow or local progression after TKI therapy and would continue single-agent EGFR TKI until physician assessment PD were enrolled in this study. Physician assessment PD was defined as symptomatic progression and/or multiple progression ( $\geq$ four sites of extracranial progression) and/or vital organ progression. Patients may undergo necessary local therapy or treatment (radiation therapy, radiofrequency ablation, gamma knife radiosurgery, or ultrasound-guided drainage plus bleomycin injection to the thoracic cavity) for a site of progressive disease.

As some patients currently do not have their tumor EGFR mutation status determined before starting on EGFR TKI, the following criteria were used to screen patients who may benefit from the continuation of TKI according to the Jackman's definition of acquired resistance: [15] 
A. A tumor that harbors an EGFR mutation known to be associated with drug sensitivity (i.e., G719X, exon 19 deletions, L858R, and L861Q).

B. Objective clinical benefit from treatment with an EGFR TKI as defined by either of the following:

i. Documented partial or complete response (RECIST) or

ii. Significant and enduring ( $\geq 6$ months) clinical benefit (stable disease as defined by RECIST) after initiation of first generation EGFR TKI.

Clinical characteristics and treatment courses, including tumor EGFR mutation status and rebiopsy results if identified, were reviewed from electronic medical records of all subjects to determine the mechanism of acquired resistance. Outcomes of interest included time to RECIST PD, time to physician assessment PD, and overall survival from time of acquired resistance. Nonsmokers were defined as those who had smoked $<100$ cigarettes in their lifetime.

\section{Treatment}

All patients enrolled were orally given $150 \mathrm{mg}$ of erlotinib daily, $250 \mathrm{mg}$ of gefitinib daily, or $125 \mathrm{mg}$ of icotinib t.i.d. The patients continued treatment beyond RECIST PD until physician assessment PD, death, or unacceptable toxicity was reached, whichever came first. Patients continued oral TKI therapy during local therapy intervals.

\section{Response assessment and toxicity evaluation}

In our institute, a RECIST evaluating committee comprising experienced radiologists evaluated tumor shrinkage or progression. The date of progression was defined based on routine surveillance imaging (every 2 to 3 months) and/or symptomatic progression leading to earlier radiographic evaluation using the version of RECIST 1.1. Adverse events were graded according to the modified 4.0 version of the National Cancer Institute Common Toxicity Criteria.

\section{Statistical analysis}

Initial PFS1 was defined as the interval between the beginning of EGFR-TKI and the RECIST progression time. PFS2 was defined from the start of TKI treatment to the date at which physician assessment progression or death was noted. PFS difference was defined as the difference between PFS1 and PFS2. PFS was analyzed by Kaplan-Meier method, and log-rank test was used to compare the difference within different groups. Multivariate Cox proportional hazards regression model was used to evaluate independent predictive factors associated with PFS difference. A two-sided $P$ value of less than 0.05 was considered statistically significant. All analyses were conducted using SPSS software version 11.0 for Windows.

\section{ACKNOWLEDGMENTS}

We thank the patients and their families and all the investigators, including the physicians, nurses, and laboratory technicians who were involved in this study.

\section{CONFLICTS OF INTEREST}

All the authors declare no competing interests or potential conflicts of interests.

\section{GRANT SUPPORT}

This research did not receive any grant support.

\section{REFERENCES}

1. Rosell R, Carcereny E, Gervais R, Vergnenegre A, Massuti B, Felip E, Palmero R, Garcia-Gomez R, Pallares C, Sanchez JM, Porta R, Cobo M, Garrido P, Longo F, Moran T, Insa A, et al. Erlotinib versus standard chemotherapy as first-line treatment for European patients with advanced EGFR mutation-positive non-small-cell lung cancer (EURTAC): a multicentre, open-label, randomised phase 3 trial. Lancet Oncol. 2012; 13:239-246.

2. Zhou C, Wu YL, Chen G, Feng J, Liu XQ, Wang C, Zhang S, Wang J, Zhou S, Ren S, Lu S, Zhang L, Hu C, $\mathrm{Hu} \mathrm{C}$, Luo Y, Chen L, et al. Erlotinib versus chemotherapy as first-line treatment for patients with advanced EGFR mutation-positive non-small-cell lung cancer (OPTIMAL, CTONG-0802): a multicentre, open-label, randomised, phase 3 study. Lancet Oncol. 2011; 12:735-742.

3. Maemondo M, Inoue A, Kobayashi K, Sugawara S, Oizumi S, Isobe H, Gemma A, Harada M, Yoshizawa H, Kinoshita I, Fujita Y, Okinaga S, Hirano H, Yoshimori K, Harada T, Ogura T, et al. Gefitinib or chemotherapy for non-small-cell lung cancer with mutated EGFR. N Engl J Med. 2010; 362:2380-2388.

4. Mitsudomi T, Morita S, Yatabe Y, Negoro S, Okamoto I, Tsurutani J, Seto T, Satouchi M, Tada H, Hirashima T, Asami K, Katakami N, Takada M, Yoshioka H, Shibata K, Kudoh S, et al. Gefitinib versus cisplatin plus docetaxel in patients with non-small-cell lung cancer harbouring mutations of the epidermal growth factor receptor (WJTOG3405): an open label, randomised phase 3 trial. Lancet Oncol. 2010; 11:121-128.

5. Mok TS, Wu YL, Thongprasert S, Yang CH, Chu DT, Saijo N, Sunpaweravong P, Han B, Margono B, Ichinose Y, Nishiwaki Y, Ohe Y, Yang JJ, Chewaskulyong B, Jiang H, Duffield EL, et al. Gefitinib or carboplatin-paclitaxel in pulmonary adenocarcinoma. N Engl J Med. 2009; 361:947-957. 
6. Kobayashi S, Boggon TJ, Dayaram T, Janne PA, Kocher O, Meyerson M, Johnson BE, Eck MJ, Tenen DG, Halmos B. EGFR mutation and resistance of non-small-cell lung cancer to gefitinib. N Engl J Med. 2005; 352:786-792.

7. Yang JJ, Chen HJ, Yan HH, Zhang XC, Zhou Q, Su J, Wang Z, Xu CR, Huang YS, Wang BC, Yang XN, Zhong WZ, Nie Q, Liao RQ, Jiang BY, Dong S, et al. Clinical modes of EGFR tyrosine kinase inhibitor failure and subsequent management in advanced non-small cell lung cancer. Lung Cancer. 2013; 79:33-39.

8. Chaft JE, Oxnard GR, Sima CS, Kris MG, Miller VA, Riely GJ. Disease flare after tyrosine kinase inhibitor discontinuation in patients with EGFR-mutant lung cancer and acquired resistance to erlotinib or gefitinib: implications for clinical trial design. Clin Cancer Res. 2011; 17:6298-6303.

9. Riely GJ, Kris MG, Zhao B, Akhurst T, Milton DT, Moore E, Tyson L, Pao W, Rizvi NA, Schwartz LH, Miller VA. Prospective assessment of discontinuation and reinitiation of erlotinib or gefitinib in patients with acquired resistance to erlotinib or gefitinib followed by the addition of everolimus. Clin Cancer Res. 2007; 13:5150-5155.

10. Faehling M, Eckert R, Kamp T, Kuom S, Griese U, Sträter J, Ott G, Spengler W. EGFR-tyrosine kinase inhibitor treatment beyond progression in long-term Caucasian responders to erlotinib in advanced non-small cell lung cancer: a case-control study of overall survival. Lung Cancer. 2013; 80:306-12.

11. von Minckwitz G, du Bois A, Schmidt M, Maass N, Cufer T, de Jongh FE, Maartense E, Zielinski C, Kaufmann M, Bauer W, Baumann KH, Clemens MR, Duerr R, Uleer C, Andersson M, Stein RC, et al. Trastuzumab Beyond Progression in Human Epidermal Growth Factor Receptor 2-Positive Advanced Breast Cancer: A German Breast Group 26/Breast International Group 03-05 Study. J Clin Onco. 2009; 27:1999-2006.

12. Park K, Ahn M, Yu C, Kim S, Lin M, Sriuranpong V, Tsai C, Lee J, Kang J, Perez-Moreno P, Button P,
Gregory D, Mok T.S.K. Aspiration: first-line erlotinib (E) until and beyond recist progression (PD) in Asian patients (PTS) with EGFR mutation-positive (MUT+) NSCLC. Ann Oncol. 2014; 25:426-427.

13. Sequist LV, Yang JC, Yamamoto N, O'Byrne K, Hirsh V, Mok T, Geater SL, Orlov S, Tsai CM, Boyer M, Su WC, Bennouna J, Kato T, Gorbunova V, Lee KH, Shah R, et al. Phase III study of afatinib or cisplatin plus pemetrexed in patients with metastatic lung adenocarcinoma with EGFR mutations. J Clin Onco. 2013; 31:3327-3334.

14. Tseng JS, Yang TY, Chen KC, Hsu KH, Yu CJ, Liao WY, Tsai CR, Tsai MH, Yu SL, Su KY, Chen JJ, Chen HY, Chang GC. Prior EGFR tyrosine-kinase inhibitor therapy did not influence the efficacy of subsequent pemetrexed plus platinum in advanced chemonaive patients with EGFRmutant lung adenocarcinoma. Onco Targets Ther. 2014; 7:799-805.

15. Jackman D, Pao W, Riely GJ, Engelman JA, Kris MG, Janne PA, Lynch T, Johnson BE, Miller VA. Clinical definition of acquired resistance to epidermal growth factor receptor tyrosine kinase inhibitors in non-small-cell lung cancer. J Clin Oncol. 2010; 28:357-360.

16. Marks JL, Broderick S, Zhou Q, Chitale D, Li AR, Zakowski MF, Kris MG, Rusch VW, Azzoli CG, Seshan VE, Ladanyi M, Pao W. Prognostic and therapeutic implications of EGFR and KRAS mutations in resected lung adenocarcinoma. J Thorac Oncol. 2008; 3:111-116.

17. Oxnard GR, Arcila ME, Sima CS, Riely GJ, Chmielecki J, Kris MG, Pao W, Ladanyi M, Miller VA. Acquired resistance to EGFR tyrosine kinase inhibitors in EGFR-mutant lung cancer: distinct natural history of patients with tumors harboring the T790M mutation. Clin Cancer Res. 2011; 17:1616-1622.

18. Weinstein IB. Cancer. Addiction to oncogenes-the Achilles heal of cancer. Science. 2002; 297:63-64. 